\title{
Silencing of WIPK and SIPK Mitogen-Activated Protein Kinases Reduces Tobacco mosaic virus Accumulation But Permits Systemic Viral Movement in Tobacco Possessing the $N$ Resistance Gene
}

\author{
Michie Kobayashi, ${ }^{1}$ Shigemi Seo, ${ }^{1}$ Katsuyuki Hirai, ${ }^{1,2}$ Ayako Yamamoto-Katou, ${ }^{1}$ Shinpei Katou, ${ }^{1}$ \\ Hideharu Seto, ${ }^{3}$ Tetsuo Meshi, ${ }^{1}$ Ichiro Mitsuhara, ${ }^{1}$ and Yuko Ohashi ${ }^{1}$ \\ ${ }^{1}$ Plant-Microbe Interactions Research Unit, National Institute of Agrobiological Sciences, Tsukuba, Ibaraki 305-8602, Japan; \\ ${ }^{2}$ Department of Botany, Graduate School of Science, Kyoto University, Kyoto 606-8502, Japan; ${ }^{3}$ RIKEN, Wako, Saitama \\ 351-0198, Japan
}

Submitted 10 February 2010. Accepted 30 March 2010.

\begin{abstract}
Infection of tobacco cultivars possessing the $N$ resistance gene with Tobacco mosaic virus (TMV) results in confinement of the virus by necrotic lesions at the infection site. Although the mitogen-activated protein kinases WIPK and SIPK have been implicated in TMV resistance, evidence linking them directly to disease resistance is, as yet, insufficient. Viral multiplication was reduced slightly in WIPK- or SIPK-silenced plants but substantially in WIPK/SIPKsilenced plants, and was correlated with an increase in salicylic acid (SA) and a decrease in jasmonic acid (JA). Silencing of WIPK and SIPK in a tobacco cultivar lacking the $N$ gene did not inhibit viral accumulation. The reduction in viral accumulation was attenuated by expressing a gene for an SA-degrading enzyme or by exogenously applying JA. Inoculation of lower leaves resulted in the systemic spread of TMV and formation of necrotic lesions in uninoculated upper leaves. These results suggested that WIPK and SIPK function to negatively regulate local resistance to TMV accumulation, partially through modulating accumulation of $\mathrm{SA}$ and $\mathrm{JA}$ in an $\mathrm{N}$-dependent manner, but positively regulate systemic resistance.
\end{abstract}

One of the induced disease resistance responses that plants use to defend themselves against pathogens is regulated by plant resistance $(R)$ genes whose products directly or indirectly recognize products of the corresponding pathogen avirulence (Avr) genes (Flor 1971; Dangl and Jones 2001). The absence of either an $R$ gene or the corresponding $A v r$ gene can allow the pathogen to spread beyond the initial point of infection, resulting in the development of systemic disease.

In many plant-pathogen interactions, host recognition of $A v r$ gene products triggers rapid and localized cell death at the site of pathogen invasion, known as a hypersensitive response

M. Kobayashi and S. Seo contributed equally to this work.

Corresponding author: S. Seo; Telephone: +81 (0)29 838 7440; Fax: +81 (0)29 838 7469; E-mail: sseo71@ @affrc.go.jp

Current address for S. Katou: International Young Researchers Empowerment Center, Shinshu University, Minamiminowa 8304, Nagano 399-4598, Japan.

* The $\boldsymbol{e}$-Xtra logo stands for "electronic extra" and indicates that six supplementary figures are published online.
(HR), usually resulting in the formation of necrotic lesions. HR is characterized by a set of defense responses, such as the generation of reactive oxygen species, accumulation of antimicrobial compounds, and induction of defense-related genes (Hammond-Kosack and Jones 1996). HR is thought to limit pathogens to the initial site of infection, thereby inhibiting their multiplication and spread.

Increasing evidence indicates that mitogen-activated protein kinase (MAPK) cascades play an important role in $R$ gene-mediated disease resistance. MAPK are components of signaling pathways that transduce diverse extracellular stimuli to multiple intracellular responses. In response to these stimuli, MAPK are enzymatically activated via phosphorylation by an upstream MAPK kinase (MAPKK), which, in turn, is activated by an upstream MAPKK kinase (MAPKKK) (MAPK Group 2002; Nakagami et al. 2005; Widmann et al. 1999). Avirulent pathogens induce the activation of specific plant MAPK (Romeis et al. 1999; Zhang and Klessig 1998). Genetic studies have identified components of MAPK cascades involved in $R$ gene-mediated resistance in several plant species, such as Arabidopsis, tomato, tobacco, and rice (Brader et al. 2007; del Pozo et al. 2004; Ekengren et al. 2003; Menke et al. 2004; Li et al. 2006; Sharma et al. 2003; Stulemeijer et al. 2007; Xiong and Yang 2003). Furthermore, specific MAPK have been shown to be required for full induction of defense responses during induced resistance to environmental stresses, including pathogen attack (Beckers et al. 2009).

The interaction between tobacco possessing the $N$ gene and Tobacco mosaic virus (TMV) is a classic model system for studying $R$-gene-mediated disease resistance in plants. The $N$ gene confers resistance to TMV (Holmes 1938; Whitham et al. 1994), and recognition of a 50-kDa helicase domain (p50) of the viral replicase by the $N$ gene product induces $H R$ at the site of virus invasion, resulting in the formation of necrotic lesions (Erickson et al. 1999). Several lines of evidence suggest that MAPK cascades play a role in $\mathrm{N}$-gene-mediated resistance. First, WIPK and SIPK, which are two of the best-characterized plant MAPK, are activated during an early stage of TMVinduced HR in Nicotiana tabacum cv. Xanthi nc, a tobacco cultivar possessing the $N$ gene (Zhang and Klessig 1998). Second, a gain-of-function analysis indicated that overexpression of $\mathrm{NtMEK} 2^{\mathrm{DD}}$, a constitutively active form of a tobacco MAPKK upstream of WIPK and SIPK, induces HR-like cell death in tobacco (Yang et al. 2001). Third, a transient loss-of- 
function analysis indicated that virus-induced gene silencing (VIGS) of NPK1, a MAPKKK, results in systemic spread and enhanced multiplication of TMV and compromises HR-like cell death in transgenic $N$. benthamiana plants transformed with the $N$ gene (Jin et al. 2002). A similar VIGS approach was also used to show that suppression of WIPK, SIPK, and NtMEK2 also compromises resistance to TMV (Jin et al. 2003). Furthermore, using a combination of VIGS and N. benthamiana, the NPK1-MEK/NQK1-Ntf6/NRK1 pathway was identified as another MAPK cascade involved in TMV resistance (Liu et al. 2004). These results suggest that at least two MAPK cascades are positively involved in resistance to TMV infection, possibly by regulating HR cell death. However, no loss-of-function studies on the roles of MAPK cascades in TMV resistance using tobacco cultivars possessing the $N$ gene have been reported. To define the exact role of MAPK cascades in $\mathrm{N}$-gene-mediated TMV resistance, stable transgenic tobacco plants in which WIPK, SIPK, or both were silenced were used.

\section{RESULTS}

Silencing of WIPK and SIPK inhibits TMV accumulation in tobacco cv. Samsun NN possessing the $N$ gene.

We first examined whether $N$. benthamiana expressing the $N$ gene is suitable for studying the roles of WIPK and SIPK in resistance to TMV infection and HR cell death. Leaves of transgenic $N$. benthamiana plants expressing the $N$ gene were inoculated with TMV-OM, a common strain of TMV, and incubated at $20^{\circ} \mathrm{C}$. Necrotic lesions were occasionally observed 2 to 3 days postinoculation (dpi) but almost all of them were a lesion type without clear margins. In addition, it was difficult to distinguish such lesions from wounds caused by rubbing the leaf surface for inoculation. In contrast, N. tabacum cv. Samsun NN, a TMV-resistant tobacco cultivar possessing the $N$ gene, always produced necrotic lesions with clear margins in response to infection with TMV (Supplementary Fig. S1). Therefore, we used N. tabacum cv. Samsun NN as the cultivar for studying the roles of WIPK and SIPK in resistance to TMV infection.

We have previously generated transgenic tobacco plants in which WIPK, SIPK, or both were silenced by introducing inverted repeat (IR) constructs, including 3'-untranslated regions from WIPK and SIPK cDNA clones, into N. tabacum cv. Samsun NN (Seo et al. 2007). We have shown that the SIPK protein and the WIPK protein are specifically reduced in SIPKsilenced (lines SIPKIR-3 and SIPKIR-4) and WIPK-silenced (lines WIPKIR-2 and WIPKIR-6) plants, and both proteins are reduced in WIPK- and SIPK-silenced plants (lines WIPK/SIPKIR-2 [WS2] and WIPK/SIPKIR-3 [WS3]) (Seo et al. 2007). The same six lines were used in the current study.

To assay resistance to TMV, leaves of each line were inoculated with TMV-OM and incubated at $20^{\circ} \mathrm{C}$. The size of local necrotic lesions on inoculated leaves of the WIPK/SIPKIR lines at $5 \mathrm{dpi}$, when lesion expansion had almost ceased, was smaller than in the control line (Fig. 1A; Supplementary Fig. S2). The SIPKIR and WIPKIR lines tended to produce slightly smaller necrotic lesions than the control line; however, this difference was not significant.

The amounts of TMV RNA in leaves with necrotic lesions were determined by quantitative real-time polymerase chain reaction (qRT-PCR) analysis using primers designed to amplify a region of the viral p50. The levels of TMV RNA in the WIPK/SIPKIR lines, except for SIPKIR-3, were significantly lower than those in the control line (Fig. 1B). The WIPK/ SIPKIR lines exhibited considerably reduced accumulation of TMV RNA.
Accumulation of TMV is not inhibited

in WIPK- and SIPK-silenced Samsun S tobacco plants.

The data in Figure 1 suggest that WIPK and SIPK regulate the accumulation of TMV in tobacco cultivars possessing the $N$ gene. To assess whether the regulation of TMV accumulation by WIPK and SIPK occurs in a manner dependent of the $N$ gene, WIPK and SIPK were silenced in $N$. tabacum cv. Samsun S, a TMV-susceptible tobacco cultivar lacking the $N$ gene, by introducing the IR construct into the cultivar. Two transgenic lines (lines WIPK/SIPKIR-2S and WIPK/SIPKIR$12 \mathrm{~S})$ that exhibited reduced accumulation of WIPK and SIPK transcripts (Fig. 2A) were used to investigate TMV accumulation after infection. There was no major difference in the amounts of TMV RNA in inoculated leaves between the IR lines and a transgenic Samsun $S$ line transformed with the vector alone (Fig. 2B).
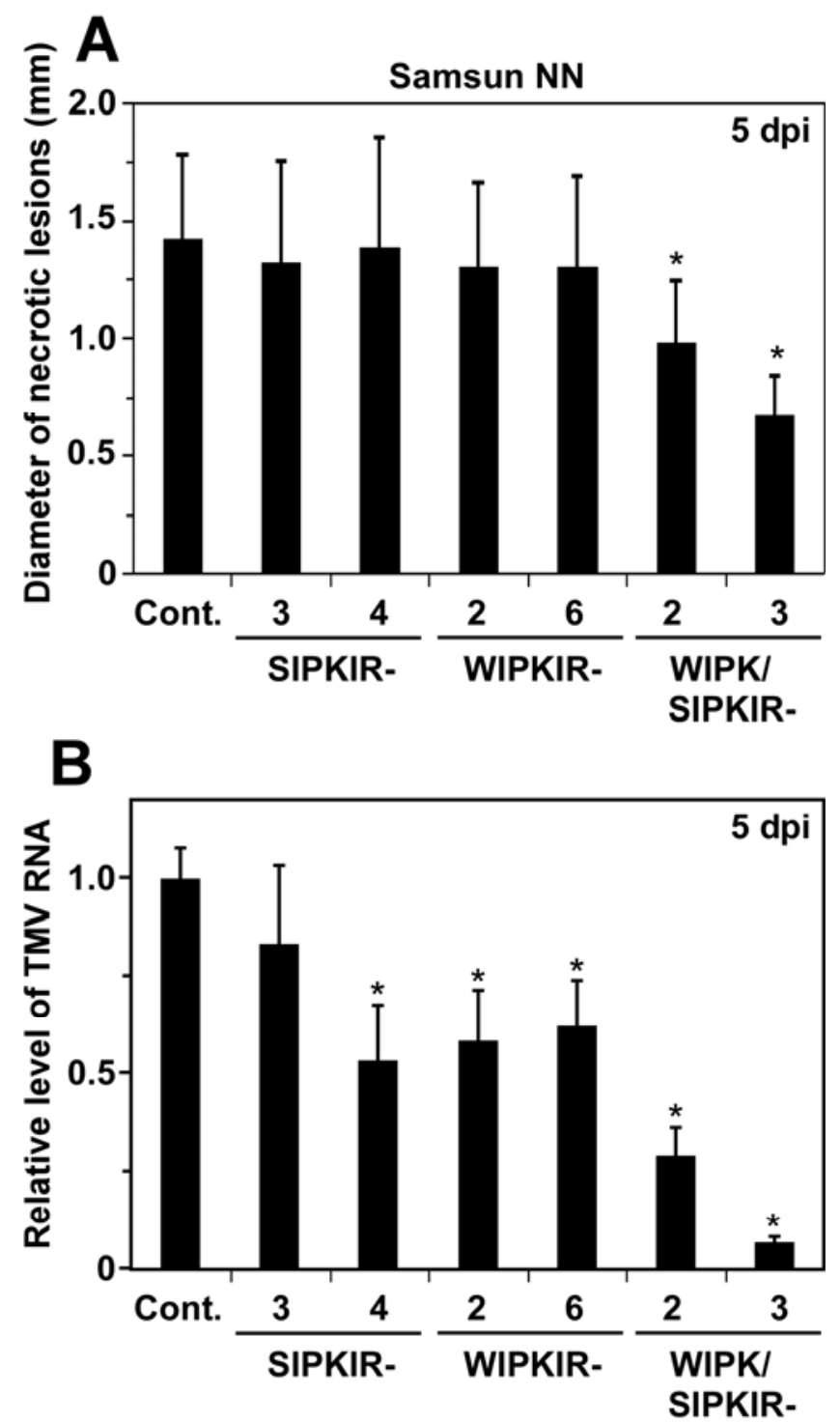

Fig. 1. Formation of necrotic lesions in Tobacco mosaic virus (TMV)inoculated leaves of mitogen-activated protein kinase-silenced Samsun NN plants. A, Diameter of local necrotic lesions at 5 days postinoculation (dpi) with TMV at $20^{\circ} \mathrm{C}$. Values are the means \pm standard deviation (SD) from 40 lesions. Asterisks indicate a significant difference from the control line (Student's $t$ test), ${ }^{*} P<0.01$. B, Quantitative real-time polymerase chain reaction analysis of TMV RNA in TMV-inoculated leaves at $5 \mathrm{dpi}$. Values are the means \pm SD from three independent measurements. Asterisks indicate significant differences from the control line (Student's $t$ test); * indicates $P<0.02$. 
Effect of silencing of WIPK and SIPK

on TMV infection-induced accumulation

of salicylic acid, jasmonic acid, and ethylene.

Accumulation of salicylic acid (SA) and jasmonic acid (JA) induces the expression of defense-related genes involved in resistance responses and is associated with TMV-induced HR (Brederode et al. 1991; Dhondt et al. 2000; Malamy et al. 1990; Seo et al. 2001). Wound- or pathogen-induced accumulation of SA and JA are regulated by WIPK and SIPK (Samuel et al. 2005; Seo et al. 2007). To examine the temporal relationship between accumulation of SA and JA and activation of WIPK and SIPK in TMV-induced HR, the endogenous amounts of SA and JA and the enzymatic activities of WIPK and SIPK were investigated in wild-type Samsun NN plant tissues after TMV infection by taking advantage of the synchronous HR induction system. Shifting TMV-infected tissues from $30^{\circ} \mathrm{C}$, a nonpermissive temperature for $\mathrm{HR}$ induction, to $20^{\circ} \mathrm{C}$ resulted in the synchronous formation of necrotic lesions in the TMV-infected region. An
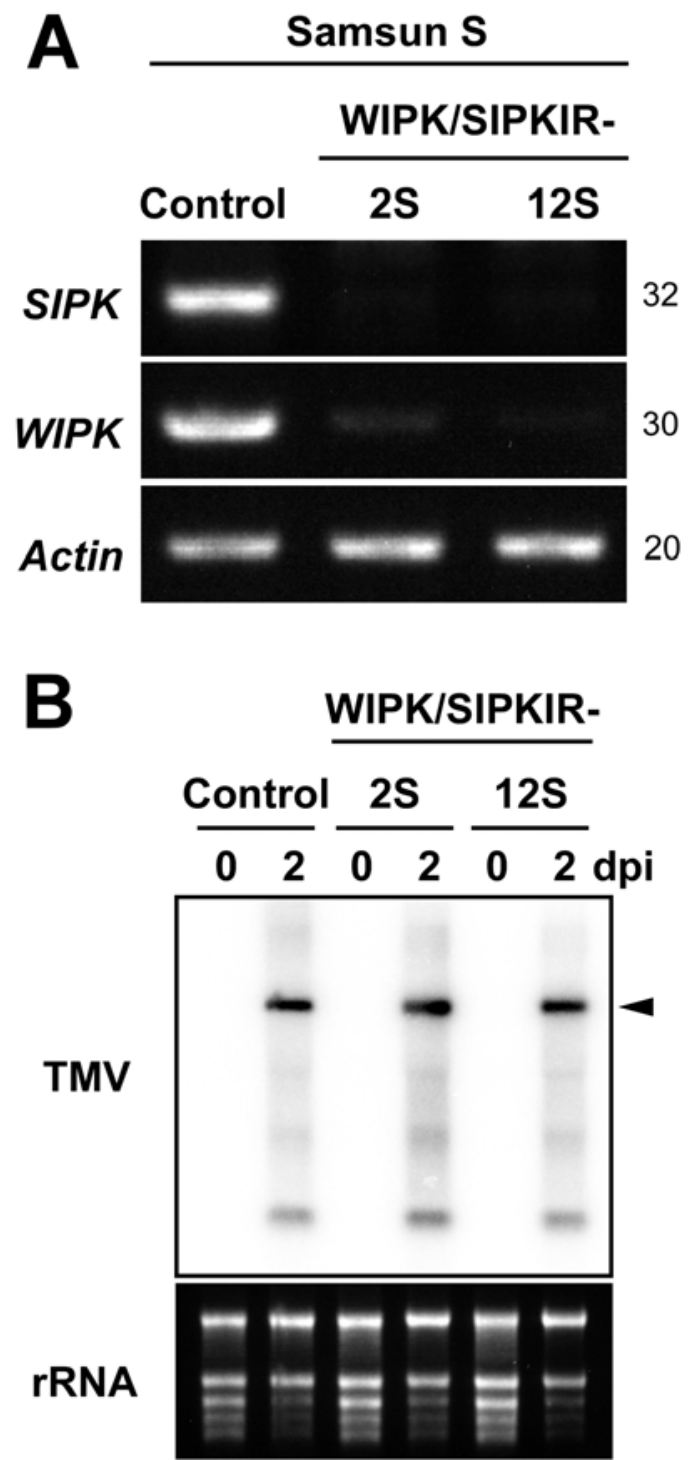

Fig. 2. Analysis of $W I P K$ - and $S I P K$-silenced Samsun S plants. A, Reversetranscriptase polymerase chain reaction (PCR) analysis of WIPK and SIPK gene expression levels in leaves. A transgenic Samsun $\mathrm{S}$ line transformed with the vector alone (Control) was used as a control. The number of PCR cycles is indicated on the right. B, RNA gel blot analysis of Tobacco mosaic virus (TMV) in TMV-inoculated leaves at 0 and 2 days postinoculation at $20^{\circ} \mathrm{C}$. rRNA levels were used to compare gel loading for total RNA. Arrowhead indicates the position of genomic RNA. increase in the kinase activities of SIPK and WIPK using myelin basic protein (MBP) as a substrate was detected $4 \mathrm{~h}$ after the temperature shift in TMV- but not mock-inoculated leaves (Fig. $3 \mathrm{~A})$. An increase in endogenous SA was detectable $2 \mathrm{~h}$ after temperature shifting of TMV-inoculated leaves from 30 to $20^{\circ} \mathrm{C}$ (Fig. 3B). JA began to accumulate $6 \mathrm{~h}$ after TMV-inoculated leaves were temperature shifted (Fig. 3C). Thus, accumulation of SA precedes activation of WIPK and SIPK and accumulation of JA during TMV-induced HR.

We next examined whether accumulation of SA and JA was altered in MAPK-silenced Samsun NN plants infected with TMV. TMV-inoculated leaf discs from each transgenic line were incubated at $30^{\circ} \mathrm{C}$ and transferred to $20^{\circ} \mathrm{C}$, and the endogenous levels of SA and JA were determined $8 \mathrm{~h}$ after the temperature shift, at which time activation of WIPK and SIPK reached a peak (Zhang and Klessig 1998). Because the phytohormone ethylene is produced during TMV-induced HR (de Laat and von Loon 1982) and because stress-induced biosynthesis of ethylene is regulated by SIPK (Kim et al. 2003; Liu and Zhang 2004), accumulation of ethylene was also examined. Levels of SA and a sugar conjugate of SA (SAG) were approximately doubled in the WIPK/SIPKIR lines (Fig. 4A). The SIPKIR-4 line and the control lines contained almost the same levels of SA and SAG, whereas the SIPKIR-3 line exhibited a slightly reduced accumulation of SA and SAG. The levels of SA and SAG in the WIPKIR lines were slightly higher than those in the control line. MAPK-silenced lines and the control line contained the almost same amount of SA before the temperature shift (Fig. 4A, $0 \mathrm{~h}$ ).

Reduced JA accumulation was observed only in the WIPK/SIPKIR lines after the temperature shift. WS2 plants produced $78 \%$ and WS3 plants produced $66 \%$ of the JA levels compared with controls (Fig. 4B). The levels of JA accumulated in the SIPKIR and WIPKIR lines were somewhat higher than in control plants. There were no significant differences in JA levels before the temperature shift in any of the lines (Fig. $4 \mathrm{~B}, 0 \mathrm{~h}$ ). JA stress induction is accompanied by transcriptional activation of enzymes involved in JA biosynthesis, such as lipoxygenase (LOX) and allene oxide cyclase (AOC) (Heitz et al. 1997; Stenzel et al. 2003). Consistent with reduced JA accumulation, accumulation of LOX and AOC transcripts after the temperature shift was reduced in the WIPK/SIPKIR lines (Supplementary Fig. S3).

Ethylene release levels from the SIPKIR and WIPK/SIPKIR lines after the temperature shift were less than half that of the control line (Fig. 4C). In contrast, the WIPKIR lines released approximately the same amount of ethylene as the control line. Ethylene release before the temperature shift was approximately the same for all lines (Fig. 4C, $0 \mathrm{~h}$ ).

\section{Effect of SA on resistance to TMV}

in WIPK- and SIPK-silenced Samsun NN plants.

The results in Figures 3 and 4 suggest that, in response to infection with TMV, WIPK and SIPK negatively regulate the accumulation of SA, whereas they positively regulate the accumulation of JA. Although the results also suggest that SIPK but not WIPK positively regulated TMV-induced accumulation of ethylene, TMV accumulation in SIPK-silenced plants was almost the same as in WIPK-silenced plants that produced normal amounts of ethylene, suggesting that any effect on TMV accumulation by WIPK and SIPK is independent of ethylene. Therefore, we focused on examining the contribution of SA and JA to the altered resistance in $M A P K$ silenced plants.

SA inhibits the multiplication of TMV in tobacco (Chivasa et al. 1997). To assess whether the higher concentration of SA in $W I P K$ - and $S I P K$-silenced plants is responsible for the reduced TMV accumulation, generation of WIPK- and SIPK- 
silenced plants expressing $N a h G$, a gene encoding an enzyme that converts SA to catechol (Gaffney et al. 1993), was attempted. However, an attempt to generate such transgenic plants did not succeed using Agrobacterium spp. Therefore, the WS3 Samsun NN line was crossed with a transgenic Xanthi nc tobacco line, which possesses the $N$ gene, expressing NahG. Two hybrid lines, WS3/NahG and NahG/WS3, for which the
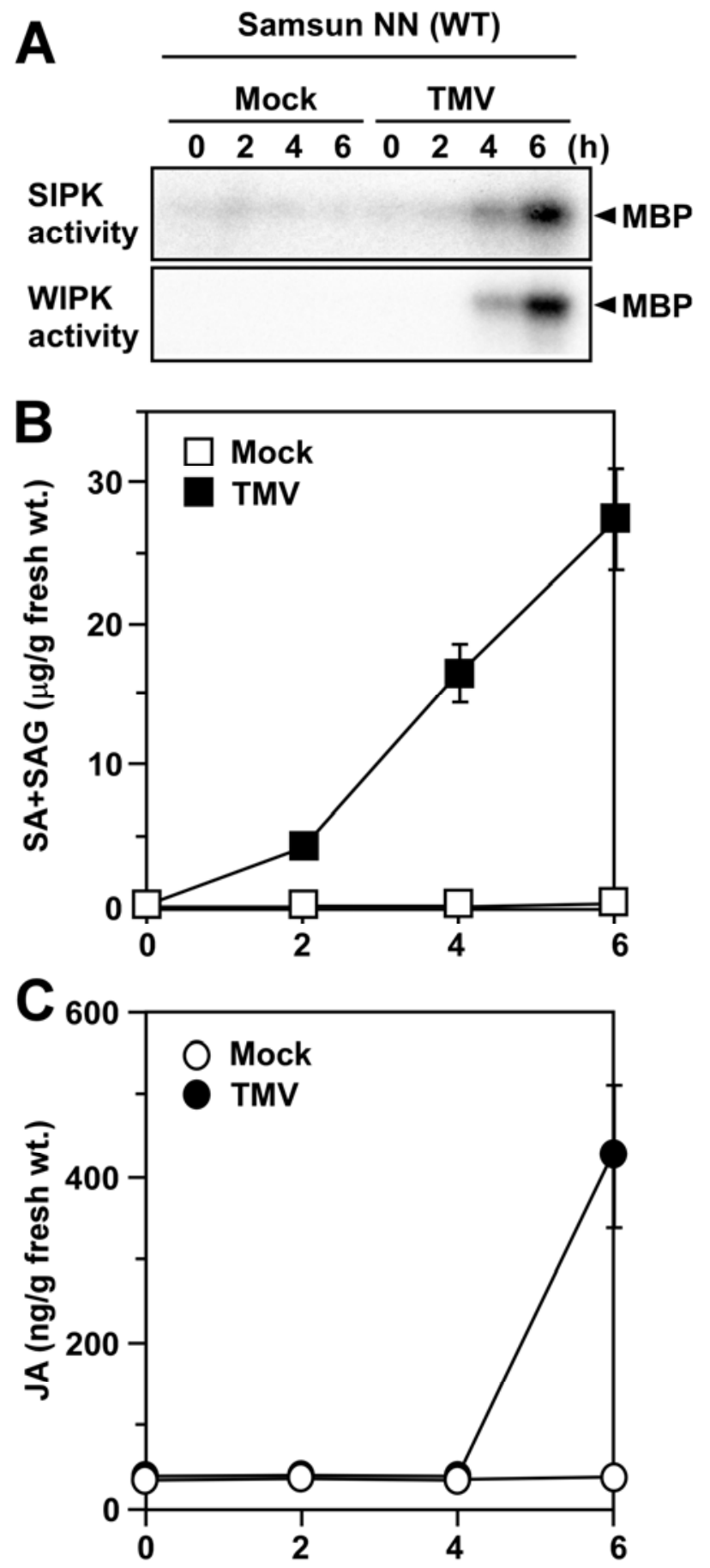

Time after temperature shift (h)

Fig. 3. Time-course analysis of mitogen-activated protein kinase activation, salicylic acid (SA) accumulation, and jasmonic acid (JA) accumulation during Tobacco mosaic virus (TMV)-induced hypersensitive response. Leaves of wild-type (WT) Samsun NN tobacco plants were inoculated with TMV, incubated at $30^{\circ} \mathrm{C}$ for $40 \mathrm{~h}$, transferred to $20^{\circ} \mathrm{C}$, and used for the measurement of myelin basic protein (MBP) kinase activity of A, SIPK and WIPK; B, SA and a sugar conjugate of SA (SAG); and C, JA. Values are the means \pm standard deviation from three independent measurements. transgenic NahG line was used as female and pollen parents, respectively, were obtained. Reverse-transcriptase PCR analysis confirmed that the WS3/NahG and NahG/WS3 lines exhibited $N a h G$ transcript accumulation and reduced accumulation of WIPK and SIPK transcripts, although the level of accumulation of $N a h G$ transcripts in these lines was lower than that in the parental NahG line (Fig. 5A).
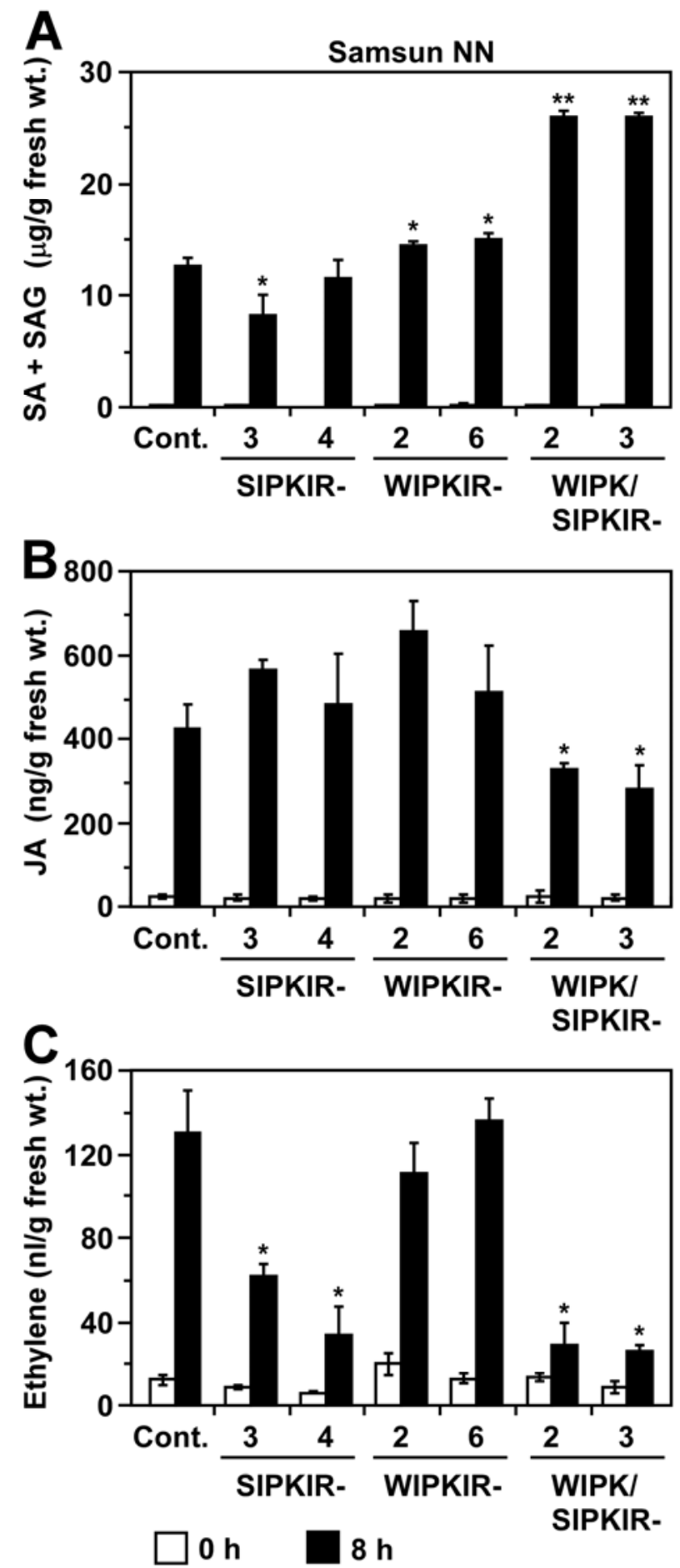

Fig. 4. Accumulation of salicylic acid (SA), jasmonic acid (JA), and ethylene in mitogen-activated protein kinase-silenced plants after a temperature shift. Tobacco mosaic virus (TMV)-inoculated leaf discs prepared from each line were harvested 0 and $8 \mathrm{~h}$ after a shift from 30 to $20^{\circ} \mathrm{C}$ and used for the measurement of $\mathbf{A}$, SA and a sugar conjugate of SA (SAG); B, JA; and $\mathbf{C}$. ethylene. Values are the means \pm standard deviation from three independent measurements. Asterisks indicate significant differences from the control line (Student's $t$ test); * and ** indicate $P<0.05$ and 0.001 , respectively. 

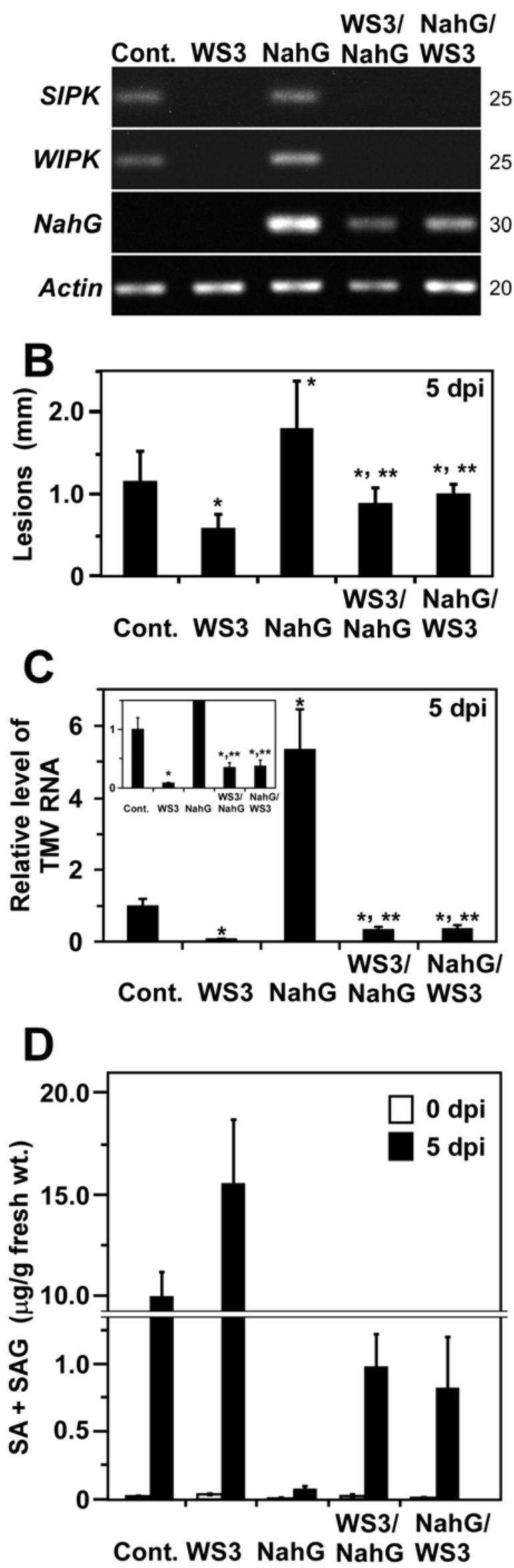

Leaves of the WS3/NahG and NahG/WS3 lines were inoculated with $\mathrm{TMV}$ and incubated at $20^{\circ} \mathrm{C}$, and the size of necrotic lesions and the level of accumulation of TMV RNA were determined at 5 dpi to evaluate resistance to TMV. The WS3/NahG and NahG/WS3 lines produced larger necrotic lesions than did the parental WS3 line (Fig. 5B). The level of TMV RNA in the hybrid lines was higher than in the parental WS3 line (Fig. 5C).

Expression of the NahG gene in tobacco plants inhibits accumulation of SA in response to infection with TMV (Gaffney et al. 1993). To assess whether the $N a h G$ gene functioned in the hybrid lines, the endogenous levels of SA and SAG in inoculated leaves were measured. NahG plants produced only small amounts of SA and SAG in response to infection; the levels of these compounds were $1 \%$ of those in the vector control line (Fig. 5D). The levels of SA and SAG in the two hybrid lines at 5 dpi were lower than in the parental WS3 line but higher than in the parental NahG line.

\section{Effect of JA on resistance to TMV}

in WIPK- and SIPK-silenced Samsun NN plants.

To assess whether the lower concentration of JA in WIPKand $S I P K$-silenced plants is responsible for the reduced TMV accumulation, the effect of exogenous JA on accumulation of TMV in these plants was tested. TMV-inoculated leaf discs were treated with methyl jasmonate (MeJA), a methyl ester form of JA, and incubated at $20^{\circ} \mathrm{C}$, and resistance to TMV was evaluated by measuring the size of necrotic lesions and the level of accumulation of TMV RNA. Exogenously applied MeJA increased the size of local necrotic lesions in a dosedependent manner in the vector control (Fig. 6A). In the presence of MeJA, necrotic lesions with dark-brown margins were formed and some of these lesions expanded along leaf veins (Fig. 6B, control). Such effects of MeJA on changes in the size and morphology of lesions were also observed for the WS3 line (Fig. 6A and B, WS3). Consistent with increased lesion size, accumulation of TMV RNA was enhanced by MeJA in the WS3 and vector control lines (Fig. 6C).

\section{Silencing of WIPK and SIPK compromises resistance} to systemic spread of TMV in Samsun NN tobacco plants.

It has been reported that silencing of WIPK and SIPK causes systemic spread of TMV in transgenic $N$. benthamiana expressing the $N$ gene (Jin et al. 2003). To examine whether TMV spreads systemically in $M A P K$-silenced Samsun NN plants, lower leaves were inoculated with TMV and the plants were incubated at $20^{\circ} \mathrm{C}$. WIPK- and SIPK-silenced plants developed systemic HR-like lesions along their veins at 10 to $15 \mathrm{dpi}$, whereas control plants did not exhibit any symptoms of lesion formation (Fig. 7A). It was confirmed that inoculation of lower

Fig. 5. Analysis of WIPK- and SIPK-silenced and NahG plants and their hybrids. The vector control line (Cont.) was used as a control. A, Reversetranscriptase polymerase chain reaction (PCR) analysis of the WIPK, $S I P K$, and NahG genes in leaves. The number of PCR cycles is indicated on the right. B, Diameter of local necrotic lesions in Tobacco mosaic virus (TMV)-inoculated leaves at 5 days postinoculation (dpi). Values are the means \pm standard deviation (SD) from 40 lesions. C, Quantitative realtime PCR analysis of TMV RNA in TMV-inoculated leaves at 5 dpi. Values are the means \pm SD from three independent measurements. The inset shows a magnification of the ordinate scale for the relative level of TMV RNA. For B and C, asterisks indicate significant differences from the control line (* indicates $P<0.02$, Student's $t$ test) and the WS3 line (** indicates $P<0.02$, Student's $t$ test). D, salicylic acid (SA) and a sugar conjugate of SA (SAG) concentrations in leaves before $(0 \mathrm{dpi})$ and after $(5 \mathrm{dpi})$ inoculation with $\mathrm{TMV}$ at $20^{\circ} \mathrm{C}$. Values are the means $\pm \mathrm{SD}$ from three independent measurements. 
leaves of WIPK- and SIPK-silenced lines other than the WS2 and WS3 lines with TMV resulted in formation of small lesions in size on inoculated leaves (Supplementary Fig. S4) and caused systemic HR-like lesions in upper leaves (Supplementary Fig. S5). Systemic HR-like lesions were also observed in SIPK- or WIPK-silenced plants (Supplementary Fig. S6).

The occurrence of systemic HR suggested that TMV spread systemically from TMV-inoculated lower leaves to the upper leaves. Different approaches were employed to examine the possibility of systemic viral spread using the WS2 or WS3 lines. RNA blot analysis of TMV in symptomatic upper leaves was performed to check for the presence of the virus. TMV RNA was detected in the WIPK/SIPKIR lines, whereas it was undetectable in the control line (Fig. 7B).

TMV translocates systemically in vascular bundles of tobacco cultivars lacking the $N$ gene. If systemic spread of TMV occurs in $W I P K$ - and $S I P K$-silenced plants, the pathogen would be detected in the vascular bundles of symptomatic upper leaves. The vascular movement of TMV was investigated by immunohistochemical analysis using petioles of upper leaves containing necrotic lesions. Strong blue signals corresponding to TMV were detected in vascular bundles in the petiole of symptomatic upper leaves of the WS3 line but not in those of the control line (Fig. 8). Brown necrotic lesions were also observed around the blue signals.

\section{DISCUSSION}

Here, we demonstrate that WIPK and SIPK negatively regulate local resistance to TMV accumulation, whereas they positively regulate resistance to systemic viral spread. A combination of VIGS and transgenic $N$. benthamiana plants transformed with the $N$ gene was used to show that suppression of WIPK, SIPK, and NtMEK2 compromises local resistance to TMV multiplication (Jin et al. 2003). Thus, our result on local resistance to TMV is different from the result reported by Jin and associates (2003). However, it should be noticed that our assay system used a native tobacco cultivar possessing the $N$ gene and did not involve Agrobacterium spp. for silencing. We believe that our results reflect the exact roles of WIPK and SIPK in $\mathrm{N}$-genemediated TMV resistance.

Inoculation of WIPK- and SIPK-silenced Samsun NN plants with TMV resulted in the formation of relatively small necrotic lesions accompanied by reduced TMV accumulation in inoculated leaves (Fig. 1). There are two possibilities for the cause of the reduction in lesion size. One is that multiplication of TMV at the infection site was inhibited, resulting in the formation of small lesions. The other is that TMV multiplication occurs normally but a resistance response that leads to a decrease in viral loads at the infection site was enhanced, resulting in the appearance of small lesions. Further studies to investigate these possibilities are required.

Because silencing of WIPK and SIPK in Samsun S tobacco, a tobacco cultivar lacking the $N$ gene, did not inhibit the accumulation of TMV (Fig. 2), it is possible that any effect of TMV accumulation by WIPK and SIPK is dependent on the $N$ gene. This is reasonable because TMV-induced activation of WIPK and SIPK does not occur in tobacco cultivars lacking the $N$ gene (Zhang and Klessig 1998), suggesting that the function of WIPK and SIPK in resistance response of tobacco plants to TMV is regulated by the $N$ gene.

Several lines of evidence indicate that SA and JA are involved in the regulation of TMV accumulation mediated by WIPK and SIPK. First, the hybrids of WIPK- and SIPK-silenced and NahG plants exhibited higher levels of TMV accumulation than did the parental WIPK- and SIPK-silenced line (Fig. 5C), suggesting that the higher concentration of SA in $W I P K$ - and $S I P K$-silenced plants contributed to the reduced TMV accumulation. However, because there was only a slight difference in the levels of TMV accumulation between the hybrid lines and the parental WIPKand $S I P K$-silenced line, the contribution of SA may be minor. Second, exogenous MeJA increased the level of TMV accumulation in WIPK- and SIPK-silenced plants (Fig. 6C), suggesting that the lower concentration of JA in these plants also contributes to the reduced TMV accumulation. These results indicate the involvement of SA and JA in reduced TMV accumulation in $W I P K$ - and SIPK-silenced plants. However, we also observed that accumulation of TMV was slightly reduced in WIPK- or $S I P K$-silenced plants in which production of SA and JA was less affected, suggesting that a factor other than SA and JA is involved in the reduction in TMV accumulation. Therefore, it is possible that, in wild-type tobacco cultivars possessing the $N$ gene, WIPK and SIPK function to regulate TMV accumulation at the initial site of infection by modulating accumulation of SA and JA and the unknown factor.

The observation of reduced TMV accumulation is in contrast with a previous report showing that silencing of WIPK and SIPK enhances TMV multiplication in inoculated leaves of $N$. benthamiana expressing the $N$ gene (Jin et al. 2003). One possible explanation for these different results is that the functions of WIPK and SIPK or N protein or both in response to TMV are different between $N$. tabacum and $N$. benthamiana. Another possibility is due to differences in the experimental systems used. The infection of plants with Agrobacterium spp. is known to alter expression of various host genes (Ditt et al. 2001). N. benthamiana plants infected with Agrobacterium spp. may express host genes involved in enhancing TMV multiplication. The present results indicated that WIPK and SIPK are involved in negatively regulating local resistance to TMV accumulation at the infection site in tobacco. MAPK have been found to negatively regulate resistance to pathogen multiplication in several other plant-pathogen interactions (Petersen et al. 2000; Xiong and Yang 2003; Yuan et al. 2007).

VIGS of COI1, a receptor necessary for JA signaling, in $N$. benthamiana has been shown to attenuate $N$-mediated TMV resistance (Liu et al. 2004), although the authors did not examine the involvement of JA biosynthesis in resistance to TMV. Therefore, it is possible that JA biosynthesis and JA signaling are negatively and positively, respectively, involved in resistance to TMV. However, because, as described above, there is the possibility that the resistance response of $N$. tabacum to TMV is partly different from that of $N$. benthamiana to TMV, analysis using tobacco plants possessing the $N$ gene will be necessary to define the exact role of JA signaling.

The temporal analysis of signaling events revealed that accumulation of SA preceded activation of WIPK and SIPK and accumulation of JA (Fig. 3). This is partly supported by a previous report showing that SA biosynthesis precedes JA biosynthesis during Pseudomonas syringae-induced HR in tobacco (Kenton et al. 1999). Given the fact that WIPK- and SIPKsilenced Samsun NN plants exhibited enhanced SA accumulation (Fig. 4A), it is likely that activation of WIPK and SIPK is not involved in triggering SA biosynthesis but is necessary for the negative regulation of SA accumulation.

Because TMV was present in the upper leaves or petioles, forming lesions (Figs. 7 and 8), HR-like lesions in such organs are likely to be caused by the virus from inoculated leaves that has translocated through the vascular system. Thus, in WIPKand SIPK-silenced Samsun NN plants, TMV accumulation at the infection site is inhibited but systemic viral spread is permitted, suggesting that local resistance to TMV can be uncoupled from that to systemic viral spread. The results were unexpected because inhibition of systemic spread and multiplication has been generally thought to be a hallmark of the resistance re- 
sponse in TMV-resistant tobacco cultivars infected with TMV. Although it is difficult to explain the two apparently contradictory phenomena, one possible explanation is that an extremely small amount of TMV escapes from the initial site of infection before all viruses are completely limited to the site and moves systemically. A phenomenon similar to the finding in the current study has been reported for tobacco expressing deleted clones of the $N$ gene (Dinesh-Kumar and Baker 2000). It has been shown that inoculation of lower leaves of tobacco expressing deleted $N$ transcripts with TMV results in the induction of systemic HR in upper leaves, although the degree of TMV multiplication at the infection site has not been determined.

On the basis of the results from the current study, we propose the following mechanism of WIPK- and SIPK-mediated TMV

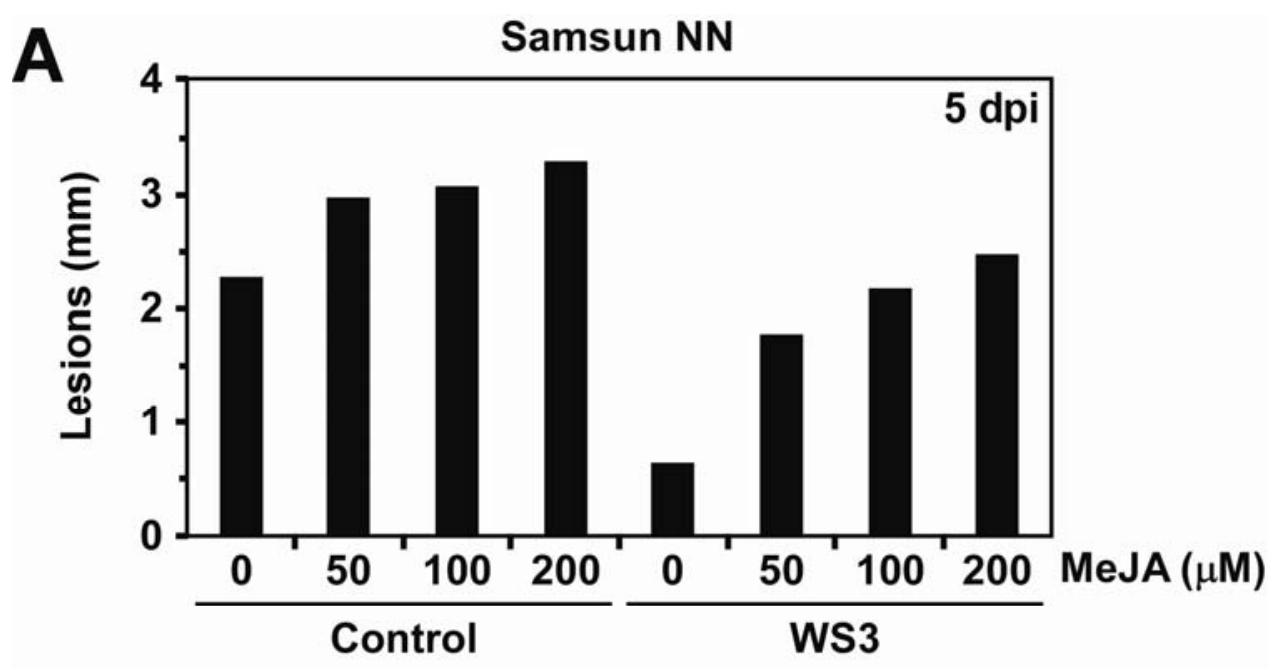

B

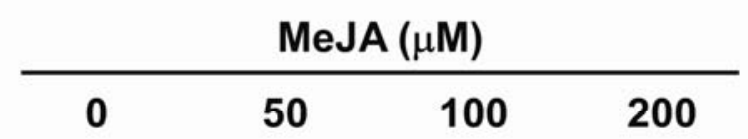

Control

WS3

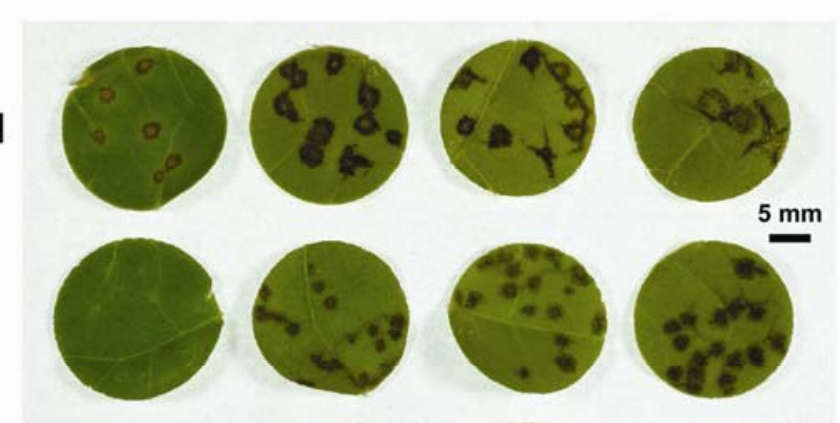

5 dpi

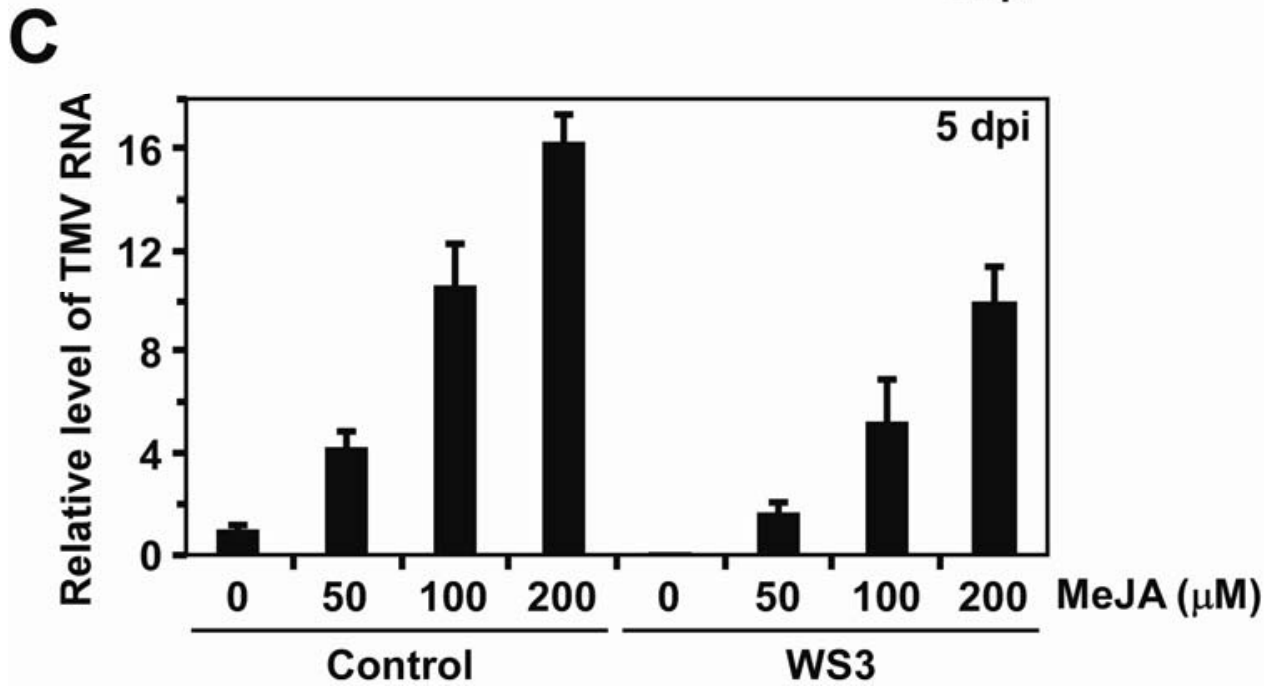

Fig. 6. Effect of exogenous methyl jasmonate (MeJA) on lesion development and Tobacco mosaic virus (TMV) accumulation. TMV-inoculated leaf discs prepared from the WS3 and vector control lines were floated on a solution containing the indicated concentrations of MeJA or 0.1\% ethanol (Control) at $20^{\circ} \mathrm{C}$ for 5 days. Treated discs were $\mathbf{A}$, used for measurement of the diameter of local necrotic lesions; $\mathbf{B}$, photographed; or $\mathbf{C}$, subjected to quantitative realtime polymerase chain reaction analysis of TMV RNA. A, Values are the means from 40 lesions. B, Bar indicates 5 mm. C, Values are the means \pm standard deviation from three independent measurements. 
resistance in tobacco possessing the $N$ gene. In response to infection with TMV, WIPK and SIPK are activated following the induction of SA biosynthesis. Activated WIPK and activated SIPK function to negatively regulate local resistance to TMV accumulation at the initial site of infection, partially through negatively regulating accumulation of the produced SA and positively regulating the accumulation of JA. On the other hand, activated WIPK and activated SIPK function to inhibit systemic spread of the virus from the infection site, although the mechanism of the inhibition remains unknown.

We have shown previously that silencing of either WIPK or SIPK reduces JA accumulation in response to wounding (Seo et al. 2007). Such nonredundant roles of WIPK and SIPK in the induction of JA accumulation after wounding have been shown for orthologs of WIPK and SIPK in other plant species (Kandoth et al. 2007; Wu et al. 2007). Interestingly, reduced JA accumulation in response to infection with TMV was observed only in $W I P K$ - and SIPK-silenced plants (Fig. 4B), suggesting that WIPK and SIPK play redundant roles in the induction of JA accumulation after infection. These results suggested that the requirement of WIPK and SIPK for JA biosynthesis induction differs depending on the kind of stresses the plant is exposed to. Despite their substantial reduced accumulation of $L O X$ and $A O C$ transcripts, WIPK- and SIPK-silenced plants exhibited only slightly reduced JA accumulation in response to infection (Fig. $4 \mathrm{~B})$. Because the mechanism of induction of JA biosynthesis is
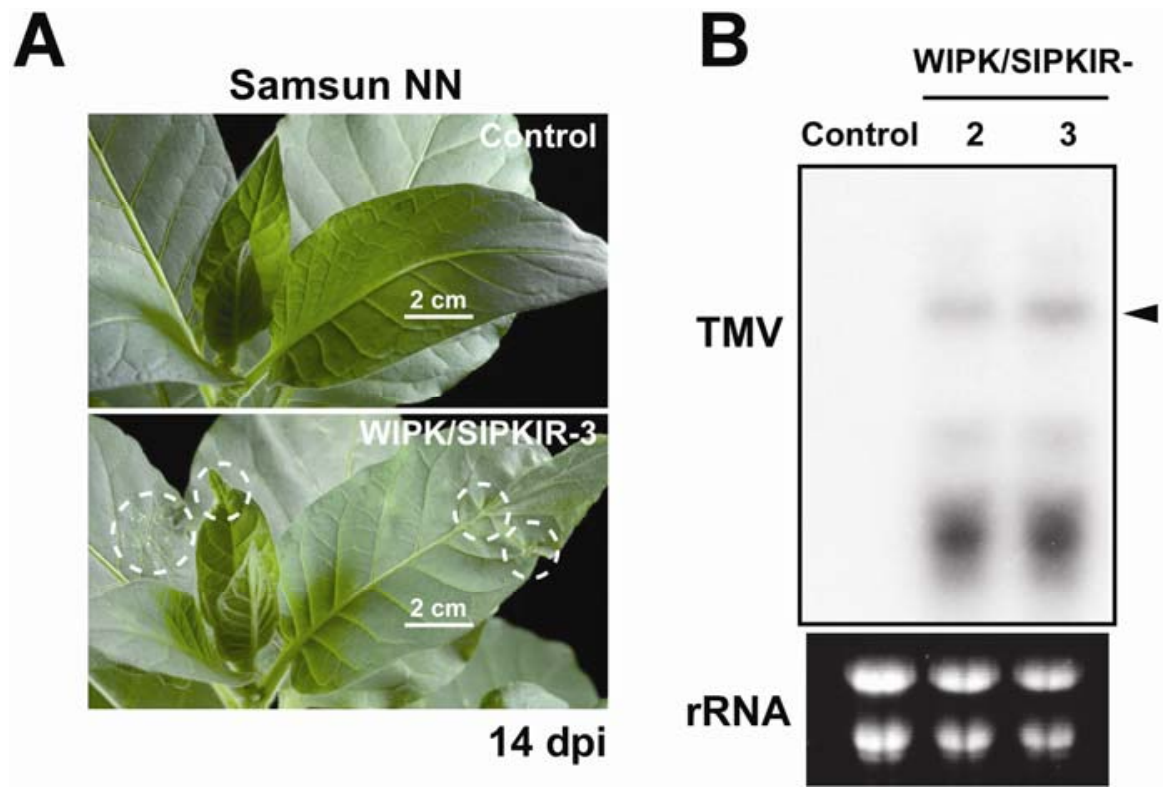

Fig. 7. Systemic hypersensitive response (HR) on the upper leaves of WIPK-and SIPK-silenced plants after inoculation of their lower leaves with Tobacco mosaic virus (TMV). A, Photograph of upper leaves of the WS3 and control lines 14 days after inoculation of their lower leaves with TMV. White dashed lines indicate the places at which HR-like lesions appeared. Bars indicate $2 \mathrm{~cm}$. B, RNA gel blot analysis of TMV in upper leaves of the WIPK/SIPKIR and control lines 14 days after inoculation of their lower leaves with TMV. rRNA levels were used to compare gel loading for total RNA. Arrowhead indicates the position of genomic RNA.

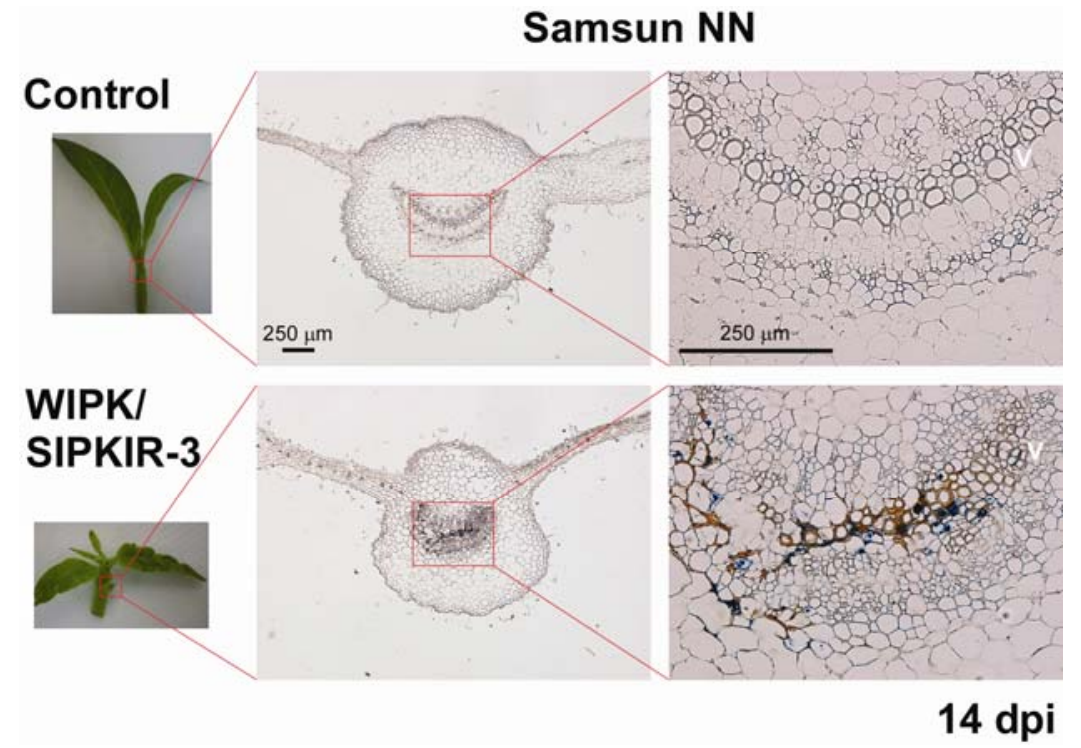

Fig. 8. Viral localization in the petiole of a leaf exhibiting necrosis of WIPK- and SIPK-silenced plants. Immunohistochemical detection of Tobacco mosaic virus (TMV) in petioles prepared from a symptomatic upper leaf of the WS3 line and from an upper leaf of the vector control (Control) 14 days after inoculation (dpi) of their lower leaves with TMV. Middle panels are close-up views of regions bounded by rectangles in the left-hand panels, and the righthand panels are close-up views of the middle panels. Bars indicate $250 \mu \mathrm{m}$. V, vascular bundles. 
not fully understood, it is difficult to explain these observations. However, one possibility is that MAPK-mediated transcriptional regulation of JA biosynthetic genes is not the sole regulator of JA biosynthesis. It has been proposed that JA biosynthesis is also regulated at the post-translational level (Schaller and Stintzi 2009).

At least two MAPK cascades are thought to be involved in TMV resistance in tobacco. One is the MEK2-SIPK/WIPK pathway (Jin et al. 2003) and the other is the NPK1MEK/NQK1-Ntf6/NRK1 pathway (Jin et al. 2002; Liu et al. 2004). However, because the involvement of the latter pathway was examined using a combination of VIGS and N. benthamiana, loss-of-function studies using stable transgenic tobacco plants will be necessary to define the exact role of this pathway. In addition, the relationship and any interaction between these two MAPK cascades remains to be clarified.

\section{MATERIALS AND METHODS}

\section{Plant materials and plant growth conditions.}

The generation of $N$. benthamiana expressing the $N$ gene has been described previously (Takabatate et al. 2007). The generation of $S I P K-$, WIPK-, and $W I P K$-and-SIPK-silenced Samsun NN tobacco plants has been described previously (Seo et al. 2007). Transgenic Xanthi nc tobacco plants expressing $N a h G$ (Gaffney et al. 1993) were used. The WS3/NahG and NahG/WS3 lines were obtained by crossing the WIPK/SIPKIR-3 line with the NahG line. The IR construct for silencing of WIPK and SIPK (Seo et al. 2007) was used to transform $N$. tabacum cv. Samsun S. Transformation and screening of transformants were performed as described previously (Seo et al. 2007). Kanamycin-resistant seedlings from the transgenic lines were transferred to pots containing vermiculite and grown in a chamber maintained at $25^{\circ} \mathrm{C}$ with $16 \mathrm{~h}$ of light $\left(120 \mu \mathrm{mol} \mathrm{m} \mathrm{m}^{-2} \mathrm{~s}^{-1}\right)$. For each analysis, 1-month-old $N$. benthamiana and 2-month-old tobacco plants were used.

\section{TMV inoculation.}

The leaf surfaces of intact plants were gently rubbed with Carborundum and TMV-OM at $0.4 \mu \mathrm{g} \mathrm{ml}^{-1}$ suspended in 10 $\mathrm{mM}$ phosphate buffer ( $\mathrm{pH}$ 7.0). After rinsing under a gentle stream of tap water, inoculated plants were incubated in a chamber maintained at 20 or $30^{\circ} \mathrm{C}$.

\section{Immunocomplex kinase assays.}

MBP kinase activity of SIPK and WIPK was measured as described previously (Seo et al. 1999).

\section{Phytohormone measurements.}

Extraction and quantification of JA was performed essentially as described previously (Baldwin et al. 1997), except that $\left[{ }^{2} \mathrm{H}_{2}\right]( \pm)$-JA was used as an internal standard (Nojiri et al. 1992). Quantification of SA and SAG was performed as described previously (Seo et al. 1995). Measurement of ethylene was performed as described previously (Ohtsubo et al. 1999).

\section{RNA extraction, RNA blotting, \\ and reverse transcriptase and qRT-PCR analyses.}

Total RNA was extracted using TRIzol reagent (Invitrogen, Carlsbad, CA, U.S.A.) in accordance with the manufacturer's instructions. Blotting and hybridization were performed as described previously (Seo et al. 1999). ${ }^{32}$ P-labeled cDNA fragments for TMV, NtLOX (National Center for Biotechnology Information [NCBI] accession number X84040), and NtAOC (NCBI accession number CAC83765) were used as probes.

For RT-PCR analysis in Figures 2A and 5A, wounded leaves $1 \mathrm{~h}$ after wounding were used as the samples, because expres- sion of the WIPK gene whose transcripts accumulate in response to wounding is undetectable in healthy leaves (Seo et al. 1995). RT-PCR was performed using an RT-PCR High-Plus kit (Toyobo, Japan) and the following primers: for WIPK, 5'-CG GTGGAGGTCAATTCCCTG-3' and 5'-CATTTACCAAAAG GTTGCTC-3'; for SIPK, 5'-GATGATGTCTGATGCGGGGG CGG-3' and 5'-GACAGTGCTCCTCAGATAAA-3'; for $N a h G$, 5'-ATCATCAACGTGGTGGCTTTCATCT-3' and 5'-CAACT CGTATAACTCGCCGGTCTC-3'; and for actin, 5'-CAGGGT TTGCTGGAGATGATGCTC-3' and 5'-TGAATGCCTGCAG CTTCCATTCC- $3^{\prime}$.

qRT-PCR analysis was performed in a two-step reaction using a SYBR Green kit (Bio-Rad, Hercules, CA, U.S.A.) and the following primers; for $p 50,5^{\prime}$-GACATGCGATGATTGGAGA AGAG-3' and 5'-GGCTGGACAACGGAGAGTAG-3', and for actin, 5'-GGGTTTGCTGGAGATGATGCT-3' and 5'-GCTTC GTCACCAACATATGCAT-3'. All data were normalized for expression of the actin gene used as an internal control.

\section{MeJA treatment.}

MeJA was purchased from Wako (Osaka, Japan), dissolved in ethanol to $100 \mathrm{mM}$, and diluted with $\mathrm{H}_{2} \mathrm{O}$. Leaf discs were floated on a solution containing MeJA at adequate concentrations; $0.1 \%$ ethanol was used as a control.

\section{Immunohistochemical analysis.}

Lateral cross-sections were prepared from petioles, fixed in $4 \%$ paraformaldehyde, and subjected to immunohistochemical analysis with anti-TMV antibody as described previously (Hirai et al. 2008).

\section{ACKNOWLEDGMENTS}

We thank Syngenta Biotechnology, Inc. (Research Triangle Park, NC, U.S.A.) for providing seed of $N a h G$ tobacco plants and M. Ishikawa, M. Nishikiori, and R. Takabatake for helpful and valuable suggestions. This work was supported by a Grant-in-Aid for Scientific Research from the Ministry of Education, Culture, Sports, Science and Technology and the Program for the Promotion of Basic Research Activities for Innovative Biosciences.

\section{LITERATURE CITED}

Baldwin, I. T., Zhang, Z. P., Diab, N., Ohnmeiss, T. E., McCloud, E. S., Lynds, G. Y., and Schmelz, E. A. 1997. Quantification, correlations and manipulations of wound-induced changes in jasmonic acid and nicotine in Nicotiana sylvestris. Planta 201:397-404.

Beckers, G. J. M., Jasklewicz, M., Liu, Y., Underwood, W. R., He, S. Y., Zhang, S., and Conrath, U. 2009. Mitogen-activated protein kinases 3 and 6 are required for full priming of stress responses in Arabidopsis thaliana. Plant Cell 21:944-953.

Brader, G., Djamei, A., Teige, M., Palva, E. T., and Hirt, H. 2007. The MAP kinase kinase MKK2 affects disease resistance in Arabidopsis. Mol. Plant-Microbe Interact. 20:589-596.

Brederode, F. T., Linthorst, H. J. M., and Bol, J. F. 1991. Differential induction of acquired resistance and PR gene expression in tobacco by virus infection, ethephon treatment, UV light and wounding. Plant Mol. Biol. 17:1117-1125.

Chivasa, S., Murphy, A. M., Naylor, M., and Carr, J. P. 1997. Salicylic acid interferes with tobacco mosaic virus replication via a novel salicylhydroxamic acid-sensitive mechanism. Plant Cell 9:547-557.

Dangl, J. L., and Jones, J. D. G. 2001. Plant pathogens and integrated defence responses to infection. Nature 411:826-833.

de Laat, A. M. M., and von Loon, L. C. 1982. Regulation of ethylene biosynthesis in virus-infected tobacco leaves. II. Time course of levels of intermediates and in vivo conversion rates. Plant Physiol. 69:240-254.

del Pozo, O., Pedley, K. F., and Martin, G. B. 2004. MAPKKK $\alpha$ is a positive regulator of cell death associated with both plant immunity and disease. EMBO (Eur. Mol. Biol. Organ.) J. 23:3072-3082.

Dhondt, S., Geoffroy, P., Stelmach, B. A., Legrand, M., and Heiz, T. 2000. Soluble phospholipase $\mathrm{A}_{2}$ activity is induced before oxylipin accumulation in tobacco mosaic virus-infected tobacco leaves and is contributed by patatin-like enzymes. Plant J. 23:431-440.

Dinesh-Kumar, S. P., and Baker, B. J. 2000. Alternatively spliced $N$ resis- 
tance gene transcripts: Their possible role in tobacco mosaic virus resistance. Proc. Natl. Acad. Sci. U.S.A. 97:1908-1913.

Ditt, R. F., Nester, E. W., and Comai, L. 2001. Plant gene expression response to Agrobacterium tumefaciens. Proc. Natl. Acad. Sci. U.S.A. 98:10954-10959.

Ekengren, S. K., Liu, Y., Schiff, M., Dinesh-Kumar, S. P., and Martin, G. B. 2003. Two MAPK cascades, NPR, and TGA transcription factors play a role in Pto-mediated disease resistance in tomato. Plant $\mathrm{J}$. 36:905-917.

Erickson, F. L., Holzberg, S., Calderon-Urrea, A., Handley, V., Axtell, M., Corr, C., and Baker, B. 1999. The helicase domain of the TMV replicase proteins induces the $\mathrm{N}$-mediated defence response in tobacco. Plant J. 18:67-75.

Flor, H. H. 1971. Current status of the gene-for-gene concept. Annu. Rev. Phytopathol. 9:275-296.

Gaffney, T., Friedrich, L., Vernooij, B., Negrotto, D., Nye, G., Ukness, S., Ward, E., Kessmann, H., and Ryals, J. 1993. Requirement of salicylic acid for the induction of systemic acquired resistance. Science 261:754756.

Hammond-Kosack, K. E., and Jones, J. D. G. 1996. Resistance gene-dependent plant defense responses. Plant Cell 8:1773-1791.

Heitz, T., Bergey, D. R., and Ryan, C. A. 1997. A gene encoding a chloroplast-targeted lipoxygenase in tomato leaves is transiently induced by wounding, systemin, and methyl jasmonate. Plant Physiol. 114:10851093.

Hirai, K., Kubota, K., Mochizuki, T., Tsuda, S., and Meshi, T. 2008. Antiviral RNA silencing is restricted to the marginal region of the dark green tissue in the mosaic leaves of Tomato mosaic virus-infected tobacco plants. J. Virol. 82:3250-3260.

Holmes, F. O. 1938. Inheritance of resistance to tobacco-mosaic disease in tobacco. Phytopathology 28:553-561.

Jin, H., Axtell, M. J., Dahlbeck, D., Ekwenna, O., Zhang, S., Staskawicz, B., and Baker, B. 2002. NPK1, an MEKK1-like mitogen-activated protein kinase kinase kinase, regulates innate immunity and development in plants. Dev. Cell 3:291-297.

Jin, H., Liu, Y., Yang, K.-Y., Kim, C. Y., Baker, B., and Zhang, S. 2003. Function of a mitogen-activated protein kinase pathway in $N$ gene-mediated resistance in tobacco. Plant J. 33:719-731.

Kandoth, P. K., Ranf, S., Pancholi, S. S., Jayanty, S., Walla, M. D., Miller, W., Howe, G. A., Lincoln, D. E., and Stratmann, J. W. 2007. Tomato MAPK LeMPK1, LeMPK2, and LeMPK3 function in the systemin-mediated defense response against herbivorous insects. Proc. Natl. Acad. Sci. U.S.A. 104:12205-12210.

Kenton, P., Mur, L. A. J., Wasternack, C., and Draper, J. 1999. (-)-Jasmonic acid accumulation in tobacco hypersensitive response lesions. Mol. PlantMicrobe Interact. 12:74-78.

Kim, C. Y., Liu, Y., Thorne, E. T., Yang, H., Fukushige, H., Gassmann, W., Hildebrand, D., Sharp, R. E., and Zhang, S. 2003. Activation of a stress-responsive mitogen-activated protein kinase cascade induces the biosynthesis of ethylene in plants. Plant Cell 15:2707-2718.

Li, Q., Xie, Q.-G, Smith-Becker, J., Navarre, D. A., and Kaloshian, I. 2006. Mi-1-mediated aphid resistance involves salicylic acid and mitogen-activated protein kinase signaling cascades. Mol. Plant-Microbe Interact. 19:655-664.

Liu, Y., and Zhang, S. 2004. Phosphorylation of 1-aminocyclopropane-1carboxylic acid synthase by MPK6, a stress-responsive mitogen-activated protein kinase, induces ethylene biosynthesis in Arabidopsis. Plant Cell 16:3386-3399.

Liu, Y., Schiff, M., and Dinesh-Kumar, S. P. 2004. Involvement of MEK1 MAPKK, NTF6 MAPK, WRKY/MYB transcription factors, COI1 and $C T R 1$ in $N$-mediated resistance to tobacco mosaic virus. Plant $\mathrm{J}$. 38:800-809.

Malamy, J., Carr, J. P., Klessig, D. F., and Raskin, I. 1990. Salicylic acid: A likely endogenous signal in the resistance response of tobacco to viral infection. Science 250:1002-1004.

MAPK Group. 2002. Mitogen-activated protein kinase cascades in plants: A new nomenclature. Trends Plant Sci. 7:301-308.

Menke, F. L. H., van Pelt, J. A., Pieterse, C. M. J., and Klessig, D. F. 2004 Silencing of the mitogen-activated protein kinase MPK6 compromises disease resistance in Arabidopsis. Plant Cell 16:897-907.

Nakagami, H., Pitzschke, A., and Hirt, H. 2005. Emerging MAP kinase pathways in plant stress signalling. Trends Plant Sci. 10:339-346.

Nojiri, H., Yamane, H., Seto, H., Yamaguchi, I., Murofushi, N., Yoshihara,
T., and Shibaoka, H. 1992. Qualitative and quantitative analysis of endogenous jasmonic acid in bulbing and non-bulbing onion plants. Plant Cell Physiol. 33:1225-1231.

Ohtsubo, N., Mitsuhara, I., Koga, M., Seo, S., and Ohashi, Y. 1999. Ethylene promotes the necrotic lesion formation and basic PR gene expression in TMV-infected tobacco. Plant Cell Physiol. 40:808-817.

Petersen, M., Brodersen, P., Naested, H., Andreasson, E., Lindhart, U., Johansen, B., Nielsen, H. B., Lacy, M., Austin, M. J., Parker, J. E., Sharma, S. B., Klessig, D. F., Martienssen, R., Mattsson, O., Jensen, A. B., and Mundy, J. 2000. Arabidopsis MAP kinase 4 negatively regulates systemic acquired resistance. Cell 103:1111-1120.

Romeis, T., Piedras, P., Zhang, S., Klessig, D. F., Hirt, H., and Jones, J. D. G. 1999. Rapid Avr9- and Cf-9-dependent activation of MAP kinases in tobacco cell cultures and leaves: Convergence of resistance gene, elicitor, wound, and salicylate responses. Plant Cell 11:273-287.

Samuel, M. A., Hall, H., Krzymowska, M., Drzewiecka, K., Hennig, J., and Ellis, B. E. 2005. SIPK signaling controls multiple components of harpin-induced cell death in tobacco. Plant J. 42:406-416.

Schaller, A., and Stintzi, A. 2009. Enzymes in jasmonate biosynthesisstructure, function, regulation. Phytochemistry 70:1532-1538.

Seo, S., Okamoto, M., Seto, H., Ishizuka, K., Sano, H., and Ohashi, Y. 1995. Tobacco MAP kinase: A possible mediator in wound signal transduction pathways. Science 270:1988-1992

Seo, S., Sano, H., and Ohashi, Y. 1999. Jasmonate-based wound signal transduction requires activation of WIPK, a tobacco mitogen-activated protein kinase. Plant Cell 11:289-298.

Seo, S., Seto, H., Yamakawa, H., and Ohashi, Y. 2001. Transient accumulation of jasmonic acid during the synchronized hypersensitive cell death in tobacco mosaic virus-infected tobacco leaves. Mol. Plant-Microbe Interact. 14:261-264.

Seo, S., Katou, S., Seto, H., Gomi, K., and Ohashi, Y. 2007. The mitogenactivated protein kinases WIPK and SIPK regulate the levels of jasmonic and salicylic acids in wounded tobacco plants. Plant J. 49:899-909.

Sharma, P. C., Ito, A., Shimizu, T., Terauchi, R., Kamoun, S., and Saitoh, H. 2003. Virus-induced silencing of WIPK and SIPK genes reduces resistance to a bacterial pathogen, but has no effect on the INF-induced hypersensitive response (HR) in Nicotiana benthamiana. Mol. Gen. Genomics 269:583-591.

Stenzel, I., Hause, B., Miersch, O., Kruz, T., Maucher., H., Weichert, H., Ziegler., J., Feussner, I., and Wasternack, C. 2003. Jasmonate biosynthesis and the allene oxide cyclase family of Arabidopsis thaliana. Plant Mol. Biol. 51:895-911.

Stulemeijer, I. J. E., Stratmann, J. W., and Joosten, M. H. A. J. 2007. Tomato mitogen-activated protein kinases LeMPK1, LeMPK2, and LeMPK3 are activated during the $\mathrm{Cf}$-4/Avr4-induced hypersensitive response and have distinct phosphorylation specificities. Plant Physiol. 144:1481-1494.

Takabatake, R., Ando, Y., Seo, S., Katou, S., Tsuda, S., Ohashi, Y., and Mitsuhara, I. 2007. MAP kinases function downstream of HSP90 and upstream of mitochondria in TMV resistance gene $N$-mediated hypersensitive cell death. Plant Cell Physiol. 48:498-510.

Whitham, S., Dinesh-Kumar, S. P., Choi, D., Hehl, R., Corr, C., and Baker, B. 1994. The product of the tobacco mosaic virus resistance gene $N$ : Similarity to Toll and the Interleukin-1 receptor. Cell 78:1101-1115.

Widmann, C., Gibson, S., Jarpe, M. B., and Johnson, G. L. 1999. Mitogenactivated protein kinase: Conservation of a three-kinase module from yeast to human. Physiol. Rev. 79:143-180.

Wu, J., Hettenhausen, C., Meldau, S., and Baldwin, I. 2007. Herbivory rapidly activates MAPK signaling in attacked and unattacked leaf regions but not between leaves of Nicotiana attenuate. Plant Cell 19:1096-1122.

Xiong, L., and Yang, Y. 2003. Disease resistance and abiotic stress tolerance in rice are inversely modulated by an abscisic acid-inducible mitogen-activated protein kinase. Plant Cell 15:745-759.

Yang, K.-Y., Liu, Y., and Zhang, S. 2001. Activation of a mitogen-activated protein kinase pathway is involved in disease resistance in tobacco. Proc. Natl. Acad. Sci. U.S.A. 98:741-746.

Yuan, B., Shen, X., Li, X., Xu, C., and Wang, S. 2007. Mitogen-activated protein kinase OsMPK6 negatively regulates rice disease resistance to bacterial pathogens. Planta 226:953-960.

Zhang, S., and Klessig, D. F. 1998. Resistance gene $N$-mediated de novo synthesis and activation of a tobacco mitogen-activated protein kinase by tobacco mosaic virus infection. Proc. Natl. Acad. Sci. U.S.A. 95:74337438 . 